DOI: $10.17976 /$ jpps/2019.02.07

\title{
УПРАВЛЕНИЕ ПОЛИТИЧЕСКИМ КОНТЕНТОМ В СОЦИАЛЬНЫХ СЕТЯХ В ПЕРИОД ПРЕДВЫБОРНОЙ КАМПАНИИ В ЭПОХУ ПОСТПРАВДЫ
}

\author{
Н.А. Рябченко, О.П. Малышева, А.А. Гнедаш
}

РЯБЧЕНКО Наталья Анатольевна, кандидат политических наук, доцент кафедры социальной работы, психологии и педагогики высшего образования, Кубанский государственный университет, Краснодар, email: rrrnatali@mail.ru; МАЛЫШЕВА Ольга Петровна, кандидат филологических наук, доцент кафедры английской филологии, Кубанский государственный университет, Краснодар, email: malisheva_83@mail.ru; ГНЕДАШ Анна Александровна, кандидат политических наук, доцент кафедры государственной политики и государственного управления, Кубанский государственный университет, Краснодар, email: anna_gnedash@inbox.ru

Рябченко Н.А., Малышева О.П., Гнедаш А.А. Управление политическим контентом в социальных сетях в период предвыборной кампании в эпоху постправды. - Полис. Политические исследования. 2019. № 2. С. 92-106. https://doi.org/10.17976/jpps/2019.02.07

Исследование выполнено при финансовой поддержке РФФИ (Отделение гуманитарных и общественных наук) в рамках научного проекта № 18-011-00910 “Модели и практики управления политическим контентом в онлайн-пространстве современных государств в эпоху постправды” (2018-2020 гг., рук. Н.А. Рябченко).

Статья поступила в редакцию: 18.12.2017. Принята к печати: 14.05.2018

Аннотация. Современный социально-политический дискурс на разных уровнях коммуникации оперирует понятиями постправды, политики постправды и фейковых новостей, интерес к которым возник в связи с референдумом Brexit и предвыборной кампанией кандидатов в президенты США 2016 г. Данные события привели к необходимости пересмотра степени влияния онлайн-пространства на развитие социально-политических систем в мире и определили необходимость исследования процессов формирования политического контента в онлайнпространстве на макро- и микроуровнях. Сами по себе эти процессы - сложные и нелинейные, и требуют применения гибридных методов анализа, например, сочетание сетевого подхода, математического и лингводискурсивного анализа, с помощью которых авторами было проведено исследование политического контента, сформированного в ходе предвыборной кампании Д. Трампа в 2016 г. с целью выявления особенностей его формирования и влияния на потенциальных избирателей (развитие общественного мнения, мобилизация и конструирование нужного поведения). Эмпирической базой исследования стали: в случае сетевого анализа - метаданные социальных сетей (период с сентября по декабрь 2016 г., а также с января по июль 2017 г.); в качестве основы лингводискурсивного анализа - массив сообщений, опубликованных командой Д. Трампа в ходе проведения предвыборной кампании в тех же социальных сетях. Авторы изучили процесс потребления политического контента пользователями онлайн-пространства (потенциальные и реальные группы электората). Было исследовано, как степень воспроизводства политического контента определяет роли участников социальной сети в интернет-окружении политика (лидеры мнений, сенсоры, реализаторы, читатели, репутационные игроки). Выявлены ключевые особенности политического контента, формируемого в целях успешного продвижения объекта в социальных сетях и онлайн-пространстве. Исследование предвыборной кампании Д. Трампа показало, что результат коммуникативных 
стратегий, направленных на достижение превосходства в онлайн-пространстве посредством продвижения в социальных медиа, может в большинстве случаев конвертироваться в политическое превосходство в офлайн-пространстве.

Ключевые слова: постправда, политика постправды, альтернативные факты, пузырь фильтров, фейковые новости, политический контент, интернет, социальные сети, классификация пользователей, лингводискурсивный анализ, предвыборная кампания Д. Трампа, Трамп.

Социально-политические события 2016 г. спровоцировали скачки частоты употребления термина post-truth в совокупности с термином post-truth politics (политика постправды) как в журналистской среде, так и в профессиональной политологической среде, а также в коммуникационных процессах социальных сетей. Повышенный интерес к политике постправды связан с обсуждением референдума Brexit в Великобритании и президентских выборов 2016 г. в США. Термины post-truth и post-truth politics прочно вошли в политическую повестку дня, продуцируя трансформационные процессы в социально-политических системах по всему миру, что в значительной мере отражено в различных российских и зарубежных исследованиях [Pearson 2017; Spohr 2017; Enli 2017]. С.В. Чугров определяет постправду как "постмодернистскую девиацию, деформированное и стереотипизированное состояние сознания, в котором стереотипы уже оторвались от реальных образов" [Чугров 2017]. Существование и развитие феномена постправды объясняется в первую очередь трансформациями политического дискурса и только потом - изменениями социокультурной среды, поскольку сама постправда становится вектором трансформации этой среды.

Самым значимым новшеством эпохи постправды при современном уровне развития информационно-коммуникационных технологий становится набор категориальных понятий, которыми описывается действительность. На смену таким категориальным диадам мировосприятия как “факт - миф”, приходит понятийно-категориальный аппарат, функционирующий в рамках диады “факт - альтернативный факт". Примером этого может служить выступление Кельян Конвей, советника президента США Д. Трампа. В ходе проведения первой пресс-конференции для $N B C N E W S$ в качестве советника президента 22 января 2017 г. Конвей, отвечая на вопросы журналиста о заявлениях, сделанных накануне пресс-секретарем Белого дома Шоном Спайсером о количестве пришедших на инаугурацию президента гостей, использовала термин "альтернативные факты" . Социальные медиа подхватили высказывание К. Конвей и провели параллель с понятием “двоемыслие” из книги Дж. Оруэлла “1984”, которое означает способность одновременно придерживаться двух противоположных точек зрения. Ханна Арендт, рассуждая об истине и политике, отмечала, что истина в политической сфере достижима, только если существует возможность публичного обсуждения различных мнений по рассматриваемому вопросу [Арендт 2014]. Правда, поддержанная фактами - это то, что возникает посредством дискуссии и обсуждений, что, собственно, и должно составлять ядро политики.

Прогресс в информационно-коммуникационных технологиях предоставляет практически безграничные возможности для коммуникации и форми-

\footnotetext{
${ }^{1}$ Conway: Press Secretary Gave "Alternative Facts”. - NBC News. 22.01.2017. URL: http://www.nbcnews. $\mathrm{com} / \mathrm{meet}-$ the-press/video/conway-press-secretary-gave-alternative-facts-860142147643 (accessed 10.12.2018).
} 
рования политического дискурса и, как следствие, политического контента, детерминирующего вектор общественного развития. Однако особенности функционирования онлайн-пространства как поля социально-политических практик все чаще приводят к формированию механизмов сдерживания публичного дискурса, таких как фейковые новости и “пузырь фильтров” [Spohr 2017]. Политика постправды, определяемая нами как новый тип политической культуры, конструирует различные версии действительности, многие из которых противоречат друг другу, поскольку все они - результат получения и передачи информации, а не объективное и абсолютное отражение истины.

Политический контент мы рассматриваем как часть отраженной сознанием акторов и воспроизведенной в вербальной и невербальной формах социальнополитической действительности. Он образует непрерывную среду - информационно-новостное поле, состоящее из дискретных сообщений, посредством которых взаимодействуют социально-политические акторы публичной сферы. Политический контент способен трансформировать социально-политическую действительность, продуцируя события - сообщение или совокупность сообщений, способных изменить расстановку сил или интересов в обществе [Мирошниченко, Морозова 2017]. Развитие информационно-коммуникационных технологий и онлайн-пространства в целом требует разработки и моделирования процессов производства и воспроизводства политического контента с целью его динамического анализа. В онлайн-пространстве политический контент формируется институциональными (сайты органов власти, политических партий, политических и государственных лидеров, онлайн-СМИ) и неинституциональными (блогеры, лидеры мнений в социальных сетях, медийные персо-

ны, сетевые сообщества, отдельные пользователи социальных сетей) акторами публичной политики. В отличие от политического контента, формируемого в офлайн-пространстве, неинституциональные акторы в онлайн-пространстве не просто потребляют политический контент, но и воспроизводят его благодаря социальным сетям и горизонтальной архитектуре онлайн-пространства в целом. Базис онлайн-пространства - социальные сети; любой актор публичной сферы так или иначе должен отражать свою деятельность в них; именно они - база социальных медиа с самой большой аудиторией потребления контента [Кёхлер 2013]. Поэтому необходимо изучать политический контент в онлайн-пространстве, поскольку, с одной стороны, уровень достоверности распространяемой в социальных сетях информации, которая может составить ядро политического контента, различен и зачастую пользователи не проверяют источники, публикующие ее; с другой стороны, сетевые технологии в совокупности с определенным политическим контентом способны мобилизовать пользователей/граждан для социального действия в офлайн.

\section{МЕТОДОЛОГИЯ: СТАРТОВЫЕ ТОЧКИ АНАЛИЗА}

Социальные приложения и социальные платформы как технологические посредники коммуникации в онлайн-пространстве позволяют проанализировать взаимодействие пользователей с применением множества сетевых данных (геопозиционирование, $I D$-номер, контент-активность в виде сообщений, комментариев, лайков и хэштегов), которые осознанно или безотчетно оставляют пользователи различных групп и сообществ в интернетпространстве [Быков 2017]. Эти данные составляют эмпирическую базу исследований, в основе которых лежит конвергентная парадигма научного знания - 
междисциплинарность [Рябченко 2016], обуславливающая развитие инновационных направлений, таких как Digital humanities и Big Data. Одним из направлений в Digital humanities является сетевой анализ, базирующийся на математической теории графов и теории сложных сетей. С помощью него можно описать и проанализировать процессы, протекающие в них, такие как деятельность безмасштабных сетей, моделирующихся и анализирующихся как графы, у которых число связей, входящих в структуру их вершин, распределяется по степенному закону, выраженному в виде математической формулы: $P(k) \sim k^{-\alpha}$ [Albert, Barabasi 2002: 47], где $k$ - количество связей пользователя в социальной сети и $\alpha-$ постоянная величина, принимающая значения от двух до трех.

Рассматривая сетевые сообщества с точки зрения общественных наук, авторы исследования определяют их как неиерархичные и самовоспроизводящиеся социальные объединения акторов/групп акторов, связанных общими ценностями, целями и участием в едином информационно-коммуникационном поле. Каждая социальная сеть и сетевое сообщество, функционирующие в онлайн-пространстве, по сути, есть не что иное, как социальный граф, строящийся благодаря обмену контентом между пользователями социальной сети [Ryabchenko, Gnedash 2015]. Математическая характеристика безмасштабных сетей (распределение по степенному закону) и определение сетевых сообществ посредством аналитического инструментария общественных наук позволяют говорить о том, что социальные графы, функционирующие как безмасштабные сети, имеют небольшое количество пользователей с максимальным количеством связей при том, что подавляющая часть пользователей исследуемой социальной сети имеют незначительное количество связей. Пользователей с наибольшим количеством связей в теории безмасштабных сетей принято называть хабами. Так, например, социальный граф сетевого окружения Д. Трампа представляет собой безмасштабную сеть, график которой аппроксимируется гиперболой, поскольку иллюстрирует распределение количества связей участников по степенному закону (анализ графа будет представлен ниже).

Н.А. Рябченко и А.А. Гнедаш исследовали влияние границ социальных сетей и/или сетевых сообществ на формирование смыслового концепта, принимающегося всеми участниками онлайн-пространства и формирующего типы пользователей онлайн социальной сети [Гнедаш, Рябченко 2014]: лидеры мнений, сенсоры, реализаторы, читатели и репутационные игроки. Функцией лидеров мнений (активных авторов, или же “блогеров-тысячников”) является запуск блоговолны - инициация волнового эффекта распространения информации, следствием чего является изменение информационно-новостного поля и определение вектора развития политического контента. Сенсоры пользователи, собирающие значимую информацию в рамках конкретного смыслового концепта, а также создающие контекст новостному контенту, размещаемому лидерами мнений - в сущности моделируют восприятие политического контента онлайн-пространством в целом. Реализаторы (роль, выбираемая пользователем сознательно или нет) посредством гипертекстурируемости технологически обеспечивают распространение блоговолны. Читатели, постоянно находясь онлайн, практически не генерируют публичные сообщения, при этом условия могут повлиять на изменение роли читателя на роль реализатора. Репутационными игроками являются представители бизнеса и власти, и их включение в сетевое сообщество происходит в момент, когда оно достаточно популярно. 
Что дает теория безмасштабных сетей и применение описанной классификации пользователей исследователям социальных сетей и онлайн-пространства? Во-первых, она позволяет сделать вывод, что в социальных сетях существует ограниченное количество пользователей с большим количеством связей - лидеры мнений и сенсоры, а подавляющее число пользователей лишь с несколькими связями - читатели и реализаторы. В целом, определяя сеть как безмасштабную или сложную, мы анализируем сети, устойчивые к случайным воздействиям и повреждениям (сбоям в работе/обвалам). Экспериментальные исследования показали, что после произвольного удаления до 80\% вершин в сложных сетях происходит сохранение сети как “связанного кластера" - это означает, что сеть способна продуцировать различного рода социальные действия и влиять на внешнюю среду [Евин 2010]. При этом целенаправленное удаление вершин может привести к полному распаду сети, особенно, если это хабы.

Во-вторых, описывая системы как сложные сети, мы можем исследовать динамичность сети, поскольку каждая новая связь меняет ее топологию, что приводит к появлению новых свойств или качественному преобразованию имеющихся. Именно анализ динамики сети позволяет прогнозировать поведение сети в момент прохождения точки бифуркации, определяющей, например, в какой момент социальная сеть из состояния конструктивного действия перейдет в деструктивное [Barabasi 2009].

Пользователи редко "включаются" в онлайн-сообщества самостоятельно - это происходит по “приглашению” друзей, коллег, знакомых или же самих социальных платформ. Запрос-приглашение формируется платформой исходя из анализа предпочтений пользователя² , что приводит к персонализации контента, потребляемого пользователем, и срабатыванию эффекта “пузыря фильтров". Последствия влияния данного феномена, при котором пользователь находится в информационном пространстве, детерминируемом различными информационными системами, в том числе поисковыми системами и социальными платформами, и получает исключительно ту информацию, которая согласуется с его прошлым опытом и взглядами - контент, просмотренный им ранее, предыдущие местоположения, поисковые предпочтения и запросы, могут оказывать негативное влияние как на личность и общество, создавая информационное слепое пятно (контент, отличающийся от предыдущего опыта пользователя, становится недоступным), так и на развитие гражданской позиции, делая пользователей более уязвимыми к пропаганде и манипуляциям [Pariser 2011].

Принципы работы различных социальных платформ, использующихся гражданами, одинаковы. Помимо слепых пятен, “пузырь фильтров” благодатная почва для распространения фейков или фейковых новостей. Фейковую новость могут использовать сенсоры в качестве инструмента построения и реализации конструктивных или деструктивных практик в рамках смыслового концепта, сформированного лидерами мнений. Основная цель фейков - трансформация общественного мнения в отношении конкретного политического деятеля, организации, партии и т.д.

Таким образом, применение теории и методологии безмасштабных сетей для анализа политического контента, формируемого в процессе избирательной

\footnotetext{
${ }^{2}$ M. Zuckerberg. Building Global Community. - Facebook. 16.02.2017. URL: https://www.facebook.com/ notes/markzuckerberg/buildingglobalcommunity/10154544292806634 (accessed 10.12.2018).
} 
кампании Д. Трампа, позволило авторам описать производство и воспроизводство политического контента в онлайн-пространстве, определяющего в дальнейшем развитие социально-политических процессов в офлайн-пространстве. Лингводискурсивный анализ включил в себя: контент-анализ, дискурсивный анализ, семантический анализ тегов и хэштегов (фолксономический анализ). Лингводискурсивный анализ [Discourse and Digital Practices... 2015] был применен для изучения процессов интерпретации и создания значений и смыслов в политическом контенте, формируемом социальными сетями и сообществами в ходе предвыборной кампании Д. Трампа. Применяя метод фолксономического анализа - практики совместной категоризации пользователями создаваемого, воспроизводимого и потребляемого ими контента (тексты, медиатексты, страницы сайтов, ссылки, посты в блогах, изображения, аудиозаписи, фото, видеоклипы и т.п.) в онлайн-пространстве, - мы выделили и описали структурные и качественные характеристики политического контента.

Эмпирической базой исследования стали метаданные сетевого сообщества “Donald J. Trump”, сформированного в социальной сети Facebook и составившего базу для визуального моделирования социального графа "Сетевое окружение - Official Facebook page for Donald J. Trump" ". Массив сообщений, опубликованных командой Д. Трампа в Facebook и Twitter в ходе ведения предвыборной кампании, послужил основой для проведения лингводискурсивного анализа.

\section{РЕЗУЛЬТАТЫ ИССЛЕДОВАНИЯ: АНАЛИЗ ПОЛИТИЧЕСКОГО КОНТЕНТА В ПЕРИОД ПРЕДВЫБОРНОЙ КАМПАНИИ Д. ТРАМПА}

Д. Трамп собрал на проведение кампании в два раза меньше денег, чем его главный конкурент Х. Клинтон, однако этот фактор не стал решающим в ходе проведения предвыборной кампании, поскольку избирательный цикл строился по принципу “решают не деньги, а то, на кого и как они тратятся". Используя данные, размещенные на официальном сайте Федеральной избирательной комиссии США⿱ обоих кандидатов в ходе предвыборной кампании (см. табл.). Из таблицы видно, что главная строка расходов в бюджете предвыборной кампании это расходы на рекламу, которые существенно различаются: Д. Трамп потратил 68 млн долл., а Х. Клинтон - 237,4 млн долл. Заметна существенная разница в уровне расходов и на медиапродукцию, причиной чего является использование кандидатами разных коммуникационных и коммуникативных стратегий: Трамп делал упор в большей степени на коммуникационные стратегии, а Клинтон - на коммуникативные стратегии. Коммуникативность как нечто-в-себе и коммуникационность как нечто-в-ином [Лещев 2002: 53] неотъемлемые составляющие коммуникации, влияющие друг на друга и конструирующие реальность. Однако с развитием информационных технологий и онлайн-пространства влияние коммуникативной составляющей на бытие ослабевает, зачастую по причине конструирования альтернативных реальностей, таких как фейковое новостное поле.

\footnotetext{
${ }^{3}$ Official Facebook page for Donald J. Trump. - Facebook. URL: https://www.facebook.com/DonaldTrump (accessed 10.12.2018).

${ }^{4}$ См.: Official Page for Federal Election Commission USA. 2016. https://www.fec.gov/data/candidates/ president/?election_year $=2016 \&$ cycle $=2016 \&$ election_full=true $($ accessed 10.12 .2018$)$.
} 
Расходы кандидатов в президенты США в ходе предвыборной кампании 2016 г. (млн долл.) Comparative Table of the Candidates' Expenses in Course of US Presidential Race 2016 (millions of dollars)

\begin{tabular}{|l|c|c|}
\hline & Д. Трамп & Х. Клинтон \\
\hline $\begin{array}{l}\text { Проживание в гостиницах во время проведения } \\
\text { предвыборных мероприятий }\end{array}$ & 1,5 & 45,8 \\
\hline Консультации по организации мероприятий & 2,1 & 0,2093 \\
\hline Аренда помещений и площадок для проведения мероприятий & 1,8 & 5,0 \\
\hline Аудиовизуальные услуги & 3,3 & 0,7228 \\
\hline Медиапродукция & 0,4978 & 6,2 \\
\hline Проведение анкетирования & 2,5 & 10,1 \\
\hline Реклама & 68,0 & 237,4 \\
\hline Страхование & 0,5725 & 6,2 \\
\hline Командировочные расходы & 23,5 & 24,4 \\
\hline
\end{tabular}

Д. Трамп использовал в качестве главного механизма коммуникации интернет, в том числе социальные сети. Его коммуникационная стратегия на первом этапе предвыборной кампании сводилась к игнорированию классических каналов коммуникации (телевидения) и использованию коммуникационных алгоритмов социальных сетей. Применение этих алгоритмов заключалось в том, что политик делал различные неординарные заявления на спорные темы, тем самым обеспечивая себе топовые позиции в поисковой выдаче новостных лент социальных сетей. Это позволило избежать прямого взаимодействия с представителями классической журналистики и полностью контролировать реакцию традиционных источников СМИ, которым в сложившейся ситуации оставалось только реагировать на заявления политика без возможности задавать вопросы [Bhatia, Goodwin, Walasek 2018]. Интернет делает любой информационный посыл, в том числе рекламный месседж, максимально таргетированным. Телевидение как средство массовой коммуникации лишено такой возможности [Данилова 2009]. В результате грамотно спланированной системы управления политическим контентом кандидату в президенты Д. Трампу удалось доставить контент каждому потенциальному избирателю практически персонально: потенциальный избиратель получал тот контент, который он искал, и тот контент, который его интересовал; продуцируемый контент был не только разноплановым по содержанию, но и по-разному эмоционально окрашен, и зачастую носил откровенно популистский характер.

Сетевое взаимодействие в Instagram, Facebook, Twitter было самым ярким и значимым элементом предвыборной кампании Трампа [Соловей 2017; Kayam 2018]. Вот что нового сделала команда в плане генерации и продвижения политического контента в интернет:

- в большинстве политических процессов онлайн-пространство посредством социальных медиа опережающим образом отражает события, т.е. пользователи интернета активно обсуждают события, которые еще не произошли, но могут произойти и являются прогнозируемыми и управляемыми процессами [Keneshloo et al. 2014]; 
- негативно окрашенные новости распространяются гораздо быстрее и эффективнее позитивных и выступают в качестве консолидирующей силы по отношению к оппонентам;

- коммуникационные стратегии Д. Трампа базировались на том, что достижение превосходства в онлайн-пространстве с помощью продвижения в социальных медиа может конвертироваться в превосходство в офлайн, при этом различные социальные платформы дают разную эффективность при решении задач предвыборной кампании.

Описанные принципы ведения политической кампании в онлайн-пространстве определили Facebook и Twitter как базовые социальные медиа для реализации предвыборной кампании и решения комплексов задач. Социальная платформа Facebook - центр притяжения особых групп электората (крупный бизнес, политики, медийные персоны, представительства других медиа), анализ сетевого окружения которого дает представление об этих группах и возможность анализировать хабы внутри них, поскольку, как мы убедились выше, сетевое окружение представляет собой безмасштабную сеть.

Было проанализировано сетевое окружение официальной страницы “Donald J. Trump” в Facebook ${ }^{5}$ и на основе взаимных лайков между связанными с ней страницами построен социальный граф "Сетевое окружение - Official Facebook page for Donald J. Trump”. Социальный граф включает 826 узлов и 6817 связей между ними, но это не конечная структура - а только до второго включения: в анализ включена базовая страница "Donald J. Trump” в Facebook (нулевое включение), все страницы, отмеченные на базовой странице действием "нравится" (первое включение), а также страницы, которые "понравились” первому включению. Полученный социальный граф в полной мере достаточен и отражает близкое сетевое окружение Д. Трампа - ядро. Самым влиятельным лидером мнений, исходя из анализа связей внутри представленного социального графа, является страница "Ivanka Trump". Именно эта страница - хаб всего социального графа. Подтверждением этого вывода является анализ тепловых карт узлов “Ivanka Trump" и “Donald J. Trump". Тепловая карта социального графа строится путем раскрашивания узлов по градиенту по мере удаления от выбранного узла (с учетом веса ребер как расстояния). Тепловые карты лидеров мнений (хабов) более однородны по цвету. Тепловая карта И. Трамп более однородно окрашена по сравнению с тепловой картой Д. Трампа. Это доказывает, что именно Иванка Трамп была одной из ключевых фигур в предвыборной кампании Трампа.

До сентября 2016 г. использование Facebook было главной стратегией команды Д. Трампа. Однако осенью 2016 г. цифровая стратегия резко меняется и ее стержнем становится Twitter [Batorski, Grzywinska 2018]. Специалисты по анализу психологического таргетирования в социальных сетях из компании Cambridge Analytica проанализировали, что большая часть электората в США воспринимают Twitter-сообщения как личное общение непосредственно с каждым из них, что напоминает им давнюю традицию общения кандидатов с электоратом - не на предвыборных митингах, а на ярмарках, в магазинах и на улицах [Tracey 2017]. Ведение аккаунта в Twitter Д. Трампом имитировало беседы на улицах через простые короткие сообщения, напрямую адресованные избирателям (а не

\footnotetext{
${ }^{5}$ Official Facebook Page for Donald J. Trump. - Facebook. 2017. URL: https://www.facebook.com/ DonaldTrump (accessed 10.12.2018).
} 
через дорогую и “продажную” прессу), Twitter делал Трампа “своим парнем” для каждой категории избирателей [Smith, Hanley 2018]. Twitter использовался для прямой коммуникации с избирателями и в качестве канала влияния на мнения сторонников, оппонентов, а Facebook - для привлечения денежных средств и удержания элиты. Другими словами, Twitter давал голоса, a Facebook - деньги.

Проведенный лингвистический анализ публикаций в Facebook и Twitter показал, что сообщения, содержащие один и тот же информационный посыл, существенно различаются по нескольким характеристикам, таким как стиль (публицистический - разговорный, стиль публичного выступления - газетного заголовка), эмоциональная окраска (сдержанность - экспрессивность), а также композиционная и внутренняя структура. Результаты анализа записей в Facebook в период с сентября по декабрь 2016 г., а также с января по июль 2017 г. показали, что на официальной странице в Facebook "Donald J. Trump" применяются стратегии и приемы, характерные для публичной речи: подавляющее большинство постов сопровождаются видео, в котором Трамп произносит именно тот текст, который мы видим на его странице в Facebook; графические приемы (заглавные буквы для написания всего слова или первой буквы слова, обычно начинающегося со строчной; разделение слов дефисом/ тире для обозначения паузы; выделение жирным шрифтом слов с особым значением, а также восклицательные знаки в конце предложения).

Публикуемые сообщения структурно часто построены с помощью синтаксических средств усиления выразительности речи: анафора, эпифора, антитеза, параллелизм, градация, инверсия и др., которые, безусловно, присутствуют и в письменном тексте, однако весьма эффективны для оказания целенаправленного воздействия в риторике - публичных выступлениях, представляющих собой устное выступление. Приветственное “Thank you! / Thank you all! / Thank уоu Louisiana/Iowa!” (“Спасибо! / Спасибо всем вам! Спасибо Луизиана/Айова!”), а также "GOD BLESS AMERICA." (“Да благословит Бог Америку!") - это скорее клише, используемые президентами именно в публичных речах. В записях же, сделанных на странице в Facebook после избрания Трампа президентом, прослеживаются черты, характерные исключительно для письменного текста, причем часто текста рекламного характера: это лаконичные и емкие высказывания и слоганы, цитаты со страницы Twitter, хэштег, отдельное слово или словосочетание (“Great news! \#MAGA” - “Отличные новости! \#СделаемАмерикуСноваВеликой”) как подводка к одному из хэштегов (\#FakeNews), или аккаунтов в Twitter (@FoxNews), характерных для официальных страниц президента, апеллирующих к явлениям и событиям во время президентства Трампа (\#MAGA; \#AmericaFirst - \#ПреждеВсегоАмерика), оппозиции и предыдущему правительству (\#FollowTheMoney - \#ПроследиНаЧтоПотраченыДеньги; \#Obamacare), либо к самому президенту или его команде и сподвижникам (\#ImWithYou - \#ЯСами; \#TrumpIsWithYou - \#ТрампСВами), а также его официальной странице в Twitter (@realDonaldTrump).

В публикациях на обеих платформах заглавные буквы подчеркивают значение слова и выделяют его “интонационно", что возможно лишь во время произнесения речи, а поскольку перед нами текст - это графические средства выразительности. Например, использование заглавных букв в начале слова в нарицательных существительных, прилагательных, наречиях нетипично и неверно с грамматической точки зрения. Скорее всего, это делалось с целью формирования спроса на новый хэштег (например, \#CrookedHillary - \#МошенницаХиллари). Употреблялась аксиологическая 
лексика, экспрессивный потенциал которой усиливался заглавными буквами, а также синтаксическими повторами, например, “RIGGED system”. Примечательно, что ссылки на Twitter в Facebook в допрезидентский период редки, однако становятся постоянными во время президентства и представляют ссылку с дублированием текста, представленного раннее.

Записи в Twitter (в период с сентября 2016 по июль 2017 гг.), в отличие от публикаций в Facebook, в разы многочисленнее, лаконичнее, напористее в плане использования глагольной формы императива и экспрессивной лексики, а также не обладают признаками публичной речи (лексический и синтаксический параллелизм, градация), отрывисты и демонстрируют стиль газетных заголовков: Mar 18, 2016 "Heading to Phoneix. Will be arriving soon. Tomorrow a big day. Tremendous crowds expected! \#Trump2016 \#MakeAmericaGreatAgain" ("Направляемся в Феникс. Скоро будем. Завтра будет великий день. Ожидается невероятное скопление народа!”).

В целом стратегия формирования контента Трампа в Twitter построена на стиле газетных заголовков, сжатой информации, периодически предложения опускаются, а сообщения носят разговорно-фамильярный характер с отрывистым ритмом, например: Sep 26, 2016 “@HillaryClinton's 2008 Campaign And Supporters Trafficked In Rumors About Obama's Heritage \#DabateNight" (“Предвыборная кампания @HillaryClinton 2008 и ее сподвижники стали жертвами слухов о наследии Обамы”).

Рассмотрим подробнее структурные и содержательные особенности сообщений, составляющих контент аккаунта Д. Трампа в Twitter, содержание которого было одним из факторов, повлиявших на распределение голосов на выборах.

Структурно-композиционный уровень:

- регламентированный набор синтаксических структур (для оптимизации времени прочтения и обработки информации): Sep 4, 2016 “@tweak626: I'm at a biker rally in Perry, Kansas...and everyone is a @realDonaldTrump fan. Love it”. (“@tweak626: Я на ралли байкеров в Перри, Канзас... и все здесь фанаты @realDonaldTrump. Как же мне это нравится”);

- разговорно-фамильярный характер построения сообщений: Oct 4, 2016 "Wow, @CNN is so negative. Their panel is a joke, biased and very dumb. I'm turning to @FoxNews where we get a fair shake!” (“Ого, @CNN такие злые. Их новостная лента - это просто насмешка, предвзятость и сплошная тупость. Я выбираю @FoxNews, они ведут с нами честную игру”);

- экспрессивность, нацеленная на максимально быстрый эффект вовлечения читателя за счет воздействия на его образное мышление, создается посредством использования следующих приемов: использование заглавных букв - Sep 26, 2016 “HILLARY'S BAD TAX HABIT!” "“СКВЕРНАЯ ПРИВЫЧКА ХИЛЛАРИ ПОВЫШАТЬ НАЛОГИ!"); Sep 15, 2016 / Sep 26, 2016 "Instead of driving jobs and wealth away, AMERICA will become the WORLD'S great magnet for innovation \& job creation!” (“Вместо того, чтобы сокращать рабочие места и растрачивать благосостояние, АМЕРИКА станет мощнейшим магнитом для инноваций и создания рабочих мест в МИРОВОМ масштабе!'”); Dec 20/24 2015, Mar 20, 2016, Jul 24/27/29, 2016 “SAD!” ( “ПЕЧАЛЬНО!'); воскЛицания - Sep 26, 2016 “RT @TeamTrump: A @realDonaldTrump Administration will bring JOBS BACK! \#Debates2016” (“Администрация @realDonaldTrump привлечет РАБОЧИЕ МЕСТА ОБРАТНО [в страну]!”); призывы - Mar 8 - Oct 24, 2016 “Join the MOVEMENT!" (“Присоединяйтесь 
к ДВИЖЕНИЮ!”); использование аксиологической лексики - Sep 4, 2016 “Wow, the failing @nytimes has not reported properly on Crooked's FBI release. They are at the back of the pack - no longer a credible source” "“Ого, сплоховавшие @nytimes неверно представили информацию об основной версии ФБР о продажном правительстве. Они уже не лидеры - и больше не достоверный источник");

- рифмующийся текст, цель которого, как и рекламного слогана, закрепиться в сознании и стать вирусным: Oct 4, 2016 "Here we go - Enjoy!" ("Нy вот - Наслаждайся!");

-сжатый, отрывистый ритм: “Tune in!” (“Включайся / Врубайся / Смотри!"), "Join the MOVEMENT!”,

- эллипсис, стилистический прием, суть которого заключается в намеренном опущении слов с целью придать высказыванию выразительность, живость или ритмичность, что, однако, может быть почвой для процветания неточностей, неверной интерпретации и толкования мотивов и мыслей говорящего: Sep 3, 2016 "Great visit to Detroit church, fantastic reception, and all @CNN talks about is a small protest outside. Inside a large and wonderful crowd?' (“Потрясающий опыт посещения церкви в Детройте, великолепный прием, и все, о чем говорят @CNN-лишь небольшой протест на улице. А внутри - огромная потрясающая аудитория!");

- риторические вопросы - Sep 26, 2016 “Why isn't Hillary Clinton 50 points ahead? \#DebateNight” ("Почему Хиллари Клинтон не опережает нас на 50 очков?”); Sep 26, 2016 “@ HillaryClinton has been part of the rigged DC system for 30 years? Why would we take policy advice from her? \#Debates2016” (“@HillaryClinton была частью фальшивой системы Белого Дома в течение 30 лет? С какой стати нам следовать ее советами по проведению политики государства?”); Sep 05, 2016 "President Obama \& Putin fail to reach deal on Syria - so what else is new?" (“Президенту Обаме и Путину не удалось достичь соглашения по поводу Сирии - итак, что еще новенького?”).

Лексический уровень:

- обилие общественно-политических терминов, числительных, неологизмов: Apr 25, 2016 'Shows how weak and desperate Lyin' Ted is when he has to team up with a guy who openly can't stand him and is only 1 win and 38 losses" "“Это показывает, насколько слаб и отчаялся Lyin' Ted, потому что вынужден объединиться с парнем, который открыто заявляет, что терпеть его не может - и это только 1 победа и 38 поражений!"); Apr 23, 2016 “Pennsylvania: Cast your vote for Trump for POTUS \& ALSO vote for the TRUMP DELEGATES in your congressional district!” (“Пенсильвания: Голосуй за Трампа, потому что POTUS \& ALSO голосует за ДЕЛЕГАТОВ ТРАМПА в вашем избирательном округе!”); Jan 30, 2017 “Only 109 people out of 325,000 were detained and held for questioning. Big problems at airports were caused by Delta computer outage" ("Всего 109 человек из 325,000 были задержаны для допроса. Значительные проблемы в аэропортах были вызваны перебоями в работе компьютеров Delta”);

- использование фразеологизмов, клише, игры слов, аллюзий, устойчивых сочетаний и умышленно измененных устойчивых выражений: "at the back of the pack”, “the failing @nytimes”, Sep 4, 2016 "the Web of Lies Hillary is spinning!” (“сеть лжи, которую плетет Хиллари"); Oct 2, 2016 "I have created tens of thousands of jobs and will bring back great American prosperity. Hillary has only created jobs at the FBI and DOJ!" “"Я создал десятки тысяч рабочих мест и верну Америке былое процветание. Хиллари лишь создала рабочие места в ФБР и Министерстве юстиции" - аллюзия на причастность Х. Клинтон к скандалу, связанному 
с расследованием нарушений в налоговых отчислениях Д. Трампа, а именно якобы неверно заполненной налоговой декларации 1995 г., в которой республиканец показал убытки в размере 916 млн долл.);

- смешение официально-деловой, нейтральной и разговорной лексики для создания комического эффекта и придания тексту иронической окраски: Аpr 10, 2016 "I win a state in votes and then get non-representative delegates because they are offered all sorts of goodies by Cruz campaign. Bad system!” (“Я выигрываю выборы в голосовании, а потом получаю нерепрезентативных делегатов, потому что Круз им предлагает всякие 'вкусняшки'. Гнилая система!”); Apr 10, 2016 “"The @nytimes purposely covers me so inaccurately. I want other nations to pay the U.S. for our defense of them. We are the suckers-no more!" ("The @nytimes намеренно цитирует меня с такими неточностями. Я хочу, чтобы другие страны платили США за то, что мы их защищаем. Мы больше не будем вести себя как идиоты! (разг.)”);

- сокращения: “Crooked Hillary’s V.P. Pick” (“Выбор вице-президента Мошенницей Хиллари"), “VOTE 'T”” (“Голосуй 'Т"” / "Голосуйте за Трампа"); "DOJ" (U.S. Department of Justice "Министерство юстиции США”);

- номинативные атрибутивные группы: “Lyin' Hillary Clinton” (“Лживая Хиллари Клинтон”), “Commander-in-Chief” ("Главнокомандующий” - в зависимости от контекста имеется в виду Х. Клинтон, Б. Обама, Д. Трамп или Главнокомандующий ВВС США).

Использование различных глагольных форм:

- повелительное наклонение: Sep 6, 2016 "Join me in Pensacola, Florida this Friday at 7pm!” (“Присоединяйтесь ко мне в Пенсаколе, Флорида в эту пятницу в 7 вечера!"); Oct 11, 2016 “DON'T LET HER FOOL US AGAIN” (“НЕ ДАЙТЕ ЕЙ НАС СНОВА ОДУРАЧИТЬ”);

- форма Future Simple (в значении обещания или предсказания), позволяющая сделать акцент на обещании и реальных переменах в будущем: Dec 24, 2015 - Nov 14, 2017 "Together, WE WILL MAKE AMERICA GREAT AGAIN!" (“Вместе - МЫ ВОЗРОДИМ БЫЛОЕ ВЕЛИЧИЕ АМЕРИКИ!"); Sep 1, 2016 "Mexico will pay for the wall!" (“Мексика заплатит за стену!”); Aug 26, 2016 "Look at the poverty, crime and educational statistics. I will fix it!" " Посмотрите на бедность, преступность и статистику в образовании. Я решу эти проблемы!”); Aug 18, 2016 "They will soon be calling me MR. BREXIT!" ("Скоро они будут называть меня МИСТЕР БРЕКСИТ!”);

- форма Present Perfect, подчеркивающая реализованные проекты и предпринятые действия: Oct 2, 2016 "I have created tens of thousands of jobs... Hillary has only created jobs at the FBI and DOJ!” (“Я создал десятки тысяч рабочих мест... Хиллари лишь создала рабочие места в ФБР и Министерстве юстиции”).

Анализ показывает, что кажущиеся импульсивными и необдуманными сообщения Трампа и его команды в Twitter на самом деле - результат реализации четко спланированной предвыборной кампании в онлайн-пространстве.

\section{ВЫВОДЫ И ДАЛЬНЕЙШИЕ ПЕРСПЕКТИВЫ ИССЛЕДОВАНИЯ}

Электоральные циклы всегда были своеобразными точками роста концентрированного применения новых технологий в развитии социально-политической системы. Так, в 2007 г. в ходе проведения предвыборной кампании Б. Обамы впервые использовали технологии вирусного маркетинга для сбора денежных средств в онлайн-пространстве (например, видеохостинги 
как альтернатива телевидению) - идея состояла в том, чтобы посредством социальных медиа сделать кандидата в президенты более открытым для потенциальных избирателей, в особенности для молодежи. Все эти наработки впоследствии присутствовали в кампании Х. Клинтон, однако этого оказалось недостаточно для победы над Д. Трампом.

За время, прошедшее между избирательными кампаниями Б. Обамы и Д. Трампа, трансформировались потребности онлайн-пользователей. Проведенное исследование показало, что процессы, протекающие на микроуровне, в социальных сетях и онлайн-пространстве в целом определяют производство и воспроизводство политического контента в целом. Изменения политического контента на макроуровне трансформируют вектор развития социально-политических систем, а потенциальные и реальные группы электората, являясь безмасштабными сетями, устойчивыми к внешним воздействиям и разрушениям, хотят потреблять политический контент, сформированный таким образом, чтобы акцентировать внимание на уникальности и ценности именно этого пользователя (избирателя) для будущего президента.

В ходе ведения предвыборной кампании Д. Трампа в Facebook ключевой фигурой была Иванка Трамп. Коммуникационная стратегия в сети Twitter выстраивалась таким образом, чтобы у пользователей создавалось впечатление прямого взаимодействия с кандидатом в президенты Д. Трампом. Это сформировало информационный дисбаланс, который позволил охватить различные категории электората, при этом создавая для пользователей иллюзию того, что взаимодействие осуществляется исключительно с каждым из них.

Отдельного внимания заслуживает рассмотрение вопросов, связанных 104 с фейковыми новостями как частью предвыборной кампании Д. Трампа при ведении социальных сетей. Отличительные черты фейковых новостей - их занимательность, сенсационность и провоцирование устойчивого желания распространять их дальше - позволяют фейковым новостям запускать блоговолны как неконтролируемые, нарастающие потоки информации, делая постправду мощнейшим оружием информационных войн.

DOI: $10.17976 / \mathrm{jpps} / 2019.02 .07$

\title{
PRESIDENTIAL CAMPAIGN IN POST-TRUTH ERA: INNOVATIVE DIGITAL TECHNOLOGIES OF POLITICAL CONTENT MANAGEMENT IN SOCIAL NETWORKS POLITICS
}

\author{
N.A. Ryabchenko ${ }^{1}$, O.P. Malysheva ${ }^{1}$, A.A. Gnedash ${ }^{1}$ \\ ${ }^{1}$ Kuban State University. Krasnodar, Russia
}

RYABCHENKO, Natalia Anatolievna, Cand. Sci. (Pol. Sci.), Associate Professor, Kuban State University, email: rrrnatali@mail.ru; MALYSHEVA, Olga Petrovna, Cand. Sci. (Philology), Senior Lecturer, Kuban State University, email: malisheva_83@mail.ru; GNEDASH, Anna Aleksandrovna, Cand. Sci. (Pol. Sci.), Associate Professor, Kuban State University, email: anna_gnedash@inbox.ru

Ryabchenko N.A., Malysheva O.P., Gnedash A.A. Presidential Campaign in Post-Truth Era: Innovative Digital Technologies of Political Content Management in Social Networks Politics. - Polis. Political Studies. 2019. No. 2. P. $92-106$. (In Russ.) https://doi.org/10.17976/jpps/2019.02.07

Acknowledgements. The study was executed with financial support of the Russian Foundation for Basic Research, grant No. 18-011-00910 ("Models and Practices of Managing Political Content in Online Space of Modern States in the PostTruth Era”). 
Abstract. Modern socio-political discourse on various layers of communication exploits the notions of posttruth, post-truth politics and fake news, which became topical in the wake of the Brexit referendum and US Presidential Campaign of 2016. These events, as well as many others, caused a shift in political science and exposed a need for the reconsideration of the impact of online space on the development of socio-political systems all over the world. Besides, these events exposed a research need for political content studies in the online space at micro and macro-levels. The online processes are complex and non-linear, thus, require complex and hybrid analytical methods - for example, a combination of network analysis, mathematic analysis and linguistic and discourse analysis - the tools used by the authors of the article to study the political content produced during the Trump's US Presidential Campaign 2016. The purpose of the research was to identify the peculiarities of political content production and the impact it could have on prospective voters (such as shaping public opinion, agitation and construction of a required expected behavior). The empirical foundation of the research is metadata of the social networks, required for a network analysis; likewise, the text corpus, a set of messages produced by D. Trump's team during the US Presidential Campaign 2016 in the same social networks, was the empirical base for linguistic discourse analysis. The network analysis, which originates from the theory of complex networks, was applied to study of the process of political content consumption by online users (prospective and active voter groups), and in particular, how the production capacity of social network users, as regards the produced or spread political content, can determine their roles (the opinion leaders, the sensors, the implementers, the readers, the reputation players). The linguistic discourse analysis allowed to identify the key peculiarities of the researched political content, produced as a part of a successful marketing campaign (aimed at promoting a candidate for the presidency) in social networks and online space as a whole. The study of the Trump's US Political Campaign 2016 revealed that the online dominance, acquired via social network marketing (which is a result of communicative strategies exploitation), can convert into a political dominance in the offline space.

Keywords: post-truth, post-truth politics, alternative facts, 'filter bubble', fake news, political content management, the Internet, social networks, types of users, linguistic discourse analysis, Donald J. Trump's US Presidential Campaign.

\section{References}

Albert R., Barabasi A.-L. 2002. Statistical Mechanics of Complex Networks. - Reviews of Modern Physics.

Vol. 74. No. 2. P. 47-97. https://doi.org/10.1103/RevModPhys. 74.47

Barabasi A.-L. 2009. Scale-Free Networks: A Decade and Beyond. - Science. Vol. 325. No. 5939. P. 412-413. https://doi.org/10.1126/science.1173299

Batorski D., Grzywinska I. 2018. Three Dimensions of the Public Sphere on Facebook. - Information, Communication \& Society. Vol. 21. No. 3. P. 356-374. https://doi.org/10.1080/1369118X.2017.1281329

Bhatia S., Goodwin G.P., Walasek L. 2018. Trait Associations for Hillary Clinton and Donald Trump in News Media. A Computational Analysis. - Social Psychological and Personality Science. Vol. 9. No. 2. P. 123-130. https://doi.org/10.1177/1948550617751584

Discourse and Digital Practices: Doing Discourse Analysis in the Digital Era. 2015. Ed. by R.H. Jones, A. Chik, C.A. Hafner. L.; N.Y.: Routledge.

Enli G. 2017. Twitter as Arena for the Authentic Outsider: Exploring the Social Media Campaigns of Trump and Clinton in the 2016 US Presidential Election. - European Journal of Communication. Vol. 32. No. 1. P. 50-61. https://doi.org/10.1177/0267323116682802

Kayam O. 2018. The Readability and Simplicity of Donald Trump's Language. - Political Studies Review. Vol. 16. No. 1. P. 73-88. https://doi.org/10.1177/1478929917706844

Keneshloo Y., Cadena J., Korkmaz G., N. Ramakrishnan. 2014. Detecting and Forecasting Domestic Political Crises: A Graph-Based Approach. - Proceedings of the 2014 ACM Conference on Web Science. N.Y., USA, ACM. P. 192-196. https://doi.org/10.1145/2615569.2615698

Pariser E. 2011. The Filter Bubble: What the Internet Is Hiding from You. N.Y.: Penguin Press.

Pearson M. 2017. Teaching Media Law in a Post-truth Context: Strategies for Enhancing Learning about the Legal Risks of Fake News and Alternative Facts. - Asia Pacific Media Educator. Vol. 27. No. 1. P. 17-26. https://doi.org/10.1177/1326365X17704289

Ryabchenko N., Gnedash A. 2015. Structure, Types of Users and the Practices of Online-Social Networks as a Field of Political Practices. - International Review of Management and Marketing. Vol. 5. No. 1S. P. 115-120. URL: http://www.econjournals.com/index.php/irmm/article/view/1628/pdf (accessed 05.02.2019).

Smith D.N., Hanley E. 2018. The Anger Games: Who Voted for Donald Trump in the 2016 Election, and Why? - Critical Sociology. Vol. 44. No. 2. P. 195-212. https://doi.org/10.1177/0896920517740615 
Spohr D. 2017. Fake News and Ideological Polarization: Filter Bubbles and Selective Exposure on Social Media. - Business Information Review. Vol. 34. No. 3. P. 150-160. https://doi.org/10.1177/0266382117722446

Tracey S. 2017. Trust, Trump, and the Turnout: A Marketers Point of View. - American Behavioral Scientist. Vol. 61. No. 5. P. 526-532. https://doi.org/10.1177/0002764217701218

Arendt H. 2014. Between Past and Future: Eight Exercises in Political Thought. (Russ. ed. Arendt H. Mezhdu proshlym i budushhim. Vosem' uprazhnenij v politicheskoj mysli. Moscow: Izdatelstvovo Instituta Gajdara. 416 p.)

Bykov I.A. 2017. Mediatization of Politics in the Era of Social Media. - Journal of Politic Research. Vol. 1. No. 4. P. 15-38. (In Russ.)

Chugrov S.V. 2017. Post-truth: Transformation of Political Reality or Self-Destruction of Liberal Democracy? - Polis. Political Studies. No. 2. P. 42-59. (In Russ.) https://doi.org/10.17976/jpps/2017.02.04 Danilova A.A. 2009. Manipulirovanie slovom v sredstvah massovoi informacii [Verbal Manipulation in Mass Media]. Moscow: Dobrosvet, KDU Press. 234 p. (In Russ.)

Gnedash A.A., Ryabchenko N.A. 2014. Constructive and Destructive Socio-Political Practices in Today Russia Online-Space: Fail, Case, Mechanics. - Human. Community. Management. No. 2. P. 40-54. (In Russ.)

Köchler H. 2013. The New Social Media: Chance or Challenge for Dialogue? - Polis. Political Studies. No. 4. P. 75-87. (In Russ.) URL: http://www.politstudies.ru/en/article/4734 (accessed 04.02.2019).

Leshhev S.V. 2002. Kommunikativnoe, sledovatel'no, kommunikacionnoe [Communicative, Therefore, Communicational]. Moscow: Editorial URSS. 172 p. (In Russ.)

Miroshnichenko I.V., Morozova E.V. 2017. Network Public Policy: Outlines of Subject Field. - Polis. Political Studies. No. 2. P. 82-102. (In Russ.) https://doi.org/10.17976/jpps/2017.02.05

Ryabchenko N.A. 2016. Toponymy of Network Landscape in Online-Space. - Human. Community. Management. No. 4. P. 41-53. (In Russ.)

Solovey V.D. 2017. Digital Mythology and Donald Trump Electoral Campaign. - Polis. Political Studies. No. 5. P. 122-132. (In Russ.) https://doi.org/10.17976/jpps/2017.05.09

Yevin I.A. 2010. Introduction to the Theory of Complex Networks. - Computer Research and Modeling. Vol. 2. P. 121-141. (In Russ.) URL: http://crm-en.ics.org.ru/uploads/crmissues/crm2010-2-2/crm10201. pdf (accessed 05.02.2019).

\section{Литература на русском языке}

Арендт Х. 2014. Между прошлым и будущиим. Восемь упражнений в политической мысли. М.: Изд-во Института Гайдара. 416 с.

Быков И.А. 2017. Медиатизация политики в эпоху социальных медиа. - Журнал политических исследований. Т. 1. № 4. С. 15-38.

Гнедаш А.А., Рябченко Н.А. 2014. Конструктивные и деструктивные социально-политические практики в онлайн-пространстве современной России: “фейлы”, “кейсы”, “механики”. - Человек. Сообщество. Управление. № 2. С. 40-54.

Данилова А.А. 2009. Манипулирование словом в средствах массовой информации. М.: Добросвет, Изд-во КДУ. 234 с.

Евин И.А. 2010. Введение в теорию сложных сетей. - Компьютерные исследования и моделирование. Т. 2. № 2. C. 121-141. URL: http://crm-en.ics.org.ru/uploads/crmissues/crm2010-2-2/crm10201. pdf (accessed 05.02.2019).

Кехлер Г. 2013. Новые социальные медиа: шанс или препятствие для диалога? - Полис. Политические исследования. № 4. C. 75-87. URL: http://www.politstudies.ru/en/article/4734 (accessed 04.02.2019).

Лещев С.В. 2002. Коммуникативное, следовательно, коммуникационное. М.: Эдиториал УРСС. 172 с.

Мирошниченко И.В., Морозова Е.В. 2017. Сетевая публичная политика: контуры предметного поля. - Полис. Политические исследования. № 2. С. 82-102. https://doi.org/10.17976/jpps/2017.02.05

Рябченко Н.А. 2016. Топонимика сетевого ландшафта онлайн-пространства. - Человек. Сообщество. Управление. № 4. С. 41-53.

Соловей В.Д. 2017. Цифровая мифология и избирательная кампания Дональда Трампа. - Полис. Политические исследования. № 5. С. 122-132. https://doi.org/10.17976/jpps/2017.05.09

Чугров С.В. 2017. Post-truth: трансформация политической реальности или саморазрушение либеральной демократии? - Полис. Политические исследования. № 2. C. 42-59. https://doi.org/10.17976/ jpps/2017.02.04 